\title{
Pelatihan Budidaya Tanaman secara Hidroponik untuk Pemenuhan Kebutuhan Sayur Skala Rumah Tangga
}

\author{
Nur Hayati ${ }^{*}$, Lina Arifah Fitriyah ${ }^{2}$, Andri Wahyu Wijayadi ${ }^{3}$ \\ Universitas Hasyim Asy'ari Tebuireng Jombang, 1,2,3 \\ nurhay.ht@gmail.com ${ }^{1^{*}}$, linaarifahfitriyah@gmail.com ${ }^{2}$, diaandri@gmail.com ${ }^{3}$
}

\begin{abstract}
Ngampel Village, Ngusikan, Jombang has dry soil conditions and hot temperatures so that agricultural land is not suitable for growing vegetables. These conditions cause the community to only depend on the vegetable sellers in meeting their needs. Community Service Activities (PKM) aims to provide knowledge and skill to the community in the cultivation of vegetables in a hydroponic manner so that it can be used to meet household scale vegetables. The target of this activity is PKK ladies numbering 25 people. The stages of PKM activities include four stages: preparation, training, mentoring and evaluation. Observations were carried out in July-August 2019, training activities were carried out on 12-13 December 2019 and mentoring was carried out until 2 February 2020. The PKM activities carried out showed that indicators had been achieved. Indicators of PKM participant participation were achieved with a percentage of 100\%. Indicators of the level of understanding of the participants were reached by showing $92 \%$ of PKM participants had understood the hydroponic system cultivation material. Indicators of the level of participant skills were achieved, with $84 \%$ of PKM participants able to practice vegetable cultivation with a hydroponic system.
\end{abstract}

Keywords: cultivation; hydroponic; vegetable needs

\begin{abstract}
Abstrak
Desa Ngampel, Ngusikan, Jombang memiliki kondisi lingkungan ekstrim dan tanah kering serta suhu yang panas yang berakibat tidak sesuai apabila lahan pertanian ditanami sayuran. Kondisi demikian menyebabkan masyarakat hanya bergantung pada penjual sayur keliling dalam memenuhi kebutuhannya. Tujuan Kegiatan Pengabdian Kepada Masyarakat (PKM) ini adalah menambah pengetahuan dan keterampilan masyarakat dalam budidaya sayuran secara hidroponik sehingga dapat diaplikasikan untuk pemenuhan kebutuhan sayur skala rumah tangga. Adapun peserta kegiatan ini meliputi ibu-ibu PKK berjumlah 25 orang. Tahapan kegiatan PKM meliputi empat tahap yaitu: tahap persiapan, tahap pelatihan, tahap pendampingan dan tahap evaluasi. Observasi lokasi dilaksanakan pada bulan Juli-Agustus 2019, kegiatan PKM yang berupa pelatihan dilaksanakan pada tanggal 12-13 Desember 2019 dan pendampingan dilaksanakan sampai tanggal 2 Pebruari 2020. Kegiatan yang telah dilaksanakan memberikan hasil bahwa pasrtisipasi peserta tercapai $100 \%$; sebanyak $92 \%$ peserta memiliki pemahaman terhadap budidaya hidroponik; dan $84 \%$ peserta terampil melakukan budidaya sayuran hidroponik.
\end{abstract}

Kata Kunci: budidaya tanaman; hidroponik; kebutuhan sayur 


\section{A. PENDAHULUAN}

Sempitnya lahan dan keadaan tanah yang ekstrim bukan merupakan faktor penghambat dalam bertanam. Dewasa ini sudah banyak dilakukan penanaman melalui budidaya hidroponik yang memanfaatkan media berupa serabut kelapa dan bebatuan yang telah ditambahkan dengan larutan kombinasi nutrisi primer, sekunder serta mikro (Swastika dkk., 2018). Media lain yang digunakan misalnya sekam, serabut kelapa, serbuk gergaji, spons serta rockwool. Di samping itu, dapat pula berupa media yang bersifat menunjang tanaman misalnya pasir, batu apung serta kerikil (Susilawati, 2019). Adapun pemilihan media tanam pada teknik hidroponik harus mampu menyediakan nutrisi air dan udara bagi pertumbuhan dan perkembangan tanaman (Swastika dkk., 2018). Tallei dkk. (2017) memaparkan bahwa prinsip hidroponik adalah pemberian nutrisi untuk pertumbuhan tanaman.

Hasil analisis situasi yang telah dilakukan menunjukkan bahwa keadaan lingkungan Desa Ngampel, Kecamatan Ngusikan, Kabupaten Jombang tergolong ekstrim. Kondisi udara panas dan tanahnya kering, akibatnya lahan pertanian tersebut tidak sesuai jika ditanami sayur-sayuran. Para petani di Desa Ngampel kebanyakan menanami lahan pertanian dengan padi, tebu, dan palawija seperti cabai dan jagung. Oleh sebab itu, pemenuhan kebutuhan akan sayur di desa tersebut dengan bergantung pada penjual sayur yang berkeliling dan pasar tradisional yang letaknya cukup jauh dan memerlukan waktu kurang lebih 15-20 menit untuk menempuhnya

Dari hasil wawancara yang dilakukan dengan kepala desa setempat, penanaman sayuran di pekarangan sekitar rumah kurang efektif karena adanya gangguan dari unggas yang sering berkeliaran untuk mencari makanan di tanah. Adapun solusi yang diberikan terkait permasalahan yang dialami mitra yaitu berupa pelatihan budidaya tanaman secara hidroponik untuk memenuhi kebutuhan sayur dalam skala rumah tangga.

Teknik bertanam secara hidroponik memberikan hasil yang lebih baik dibandingkan bertanam secara tradisional menggunakan tanah dkk., 2017; Susilawati, 2019). Adapun kelebihan dari hidroponik dibanding bertanam menggunakan tanah antara lain: kondisi tempat yang cenderung bersih sehingga lebih mudah diterapkan, tanaman terlindung dari curahan hujan langsung dan penggunaan media tanam yang bersih, meminimalisir penyakit dan hama yang menyerang tanaman sehingga tanaman lebih berkualitas sehat dan awet, tanaman memiliki produktivitas tinggi serta harga jual yang tinggi (Roidah, 2014; Siregar, 2017; Susilawati, 2019; Tallei dkk., 2017). Berkaitan dengan ini, Tallei dkk. (2017) menyatakan bahwa sistem budidaya hidroponik sangat tepat diterapkan pada daerah yang minim ketersediaan air.

Kelebihan bertanam secara hidroponik juga dijelaskan oleh dkk. (2019) bahwa bertanam secara hidroponik menghasilkan tanaman dengan kualitas yang baik, bebas zat kimia dan sehat. Hidroponik juga bermanfaat untuk memenuhi kebutuhan pangan keluarga dan membantu melestarikan lingkungan, hal ini karena hidroponik mampu meningkatkan kandungan oksigen di udara sehingga dapat mengurangi tingkat pencemaran udara dan menjadikan udara lingkungan sekitar lebih segar (Hutagalung, 2017).

Sejalan dengan hasil wawancara dengan kepala desa, metode budidaya sayuran secara hidroponik dianggap sangat sesuai dilakukan di Desa Ngampel sebab menanam sayuran di tanah pekarangan atau 
lahan pertanian secara langsung tidak dapat bertahan lama karena kondisi tanah yang kering dan udara yang panas. Budidaya tanaman dengan cara hidroponik juga dapat menghindari pengrusakan tanaman oleh hewan-hewan ternak semisal ayam atau unggas lainnya yang mengais tanah untuk mendapatkan makanan. Masyarakat perlu mengetahui teknik bertanam hidroponik untuk memperkaya inovasi dalam hal teknologi bertanam. Selain itu, sistem budidaya dengan hidroponik juga belum pernah dilakukan di Desa Ngampel.

Sejalan dengan kegiatan Pengabdian Kepada Masyarakat ini, hasil kegiatan pelatihan hidroponik skala rumah tangga yang dilakukan oleh Nurdin (2018) menunjukkan bahwa kegiatan pelatihan telah meningkatkan $85 \%$ pengetahuan dan penguasaan masyarakat di Kelurahan Dutulanaa Kecamatan Limboto terhadap teknologi hidroponik sebesar dan $88 \%$ kemampuan masyarakat dalam praktikum hidroponik. Lebih lanjut, kegiatan PKM yang dilakukan Solikhah dkk. (2018) menunjukkan bahwa pelatihan hidroponik dapat meningkatkan pemahaman dan keterampilan warga di Kelurahan Kalisegoro sehingga dihasilkan kebun hidroponik. Malau dkk. (2018) juga melakukan kegiatan pelatihan bertanam menggunakan metode hidroponik sangat bermanfaat dalam meningkatkan pemahaman dan kemampuan warga di Kelurahan Mukakuning, Kota Batam. Adapun PKM hidroponik yang dilakukan oleh Hakimah dkk. (2017), memberikan hasil bahwa pelatihan hidroponik dapat meningkatkan pengetahuan warga di perumahan Kuwak Utara Ds. Ngadirejo Kediri mengenai pentingnya memanfaatkan lahan pekarangan melalui sistem hidroponik sehingga dapat membuka kesempatan menjadi wirausaha.
Dengan adanya pelatihan tentang budidaya tanaman secara hidroponik, diharapkan masyarakat memiliki wawasan dan keterampilan serta dapat mempraktekkan sendiri metode hidroponik untuk memenuhi kebutuhan sayur dalam skala rumah tangga.

\section{B. PELAKSAAAN DAN METODE}

\begin{abstract}
Kegiatan pengabdian kepada masyarakat ini dilaksanakan melalui pelatihan sekaligus pendampingan tentang budidaya sayuran dengan teknik hidroponik. Sasaran kegiatan PKM ini adalah anggota PKK Desa Ngampel, Kecamatan Ngusikan, Kabupaten Jombang yang berjumlah 25 orang yang juga bertindak sebagai mitra PKM.
\end{abstract}

Adapun tahapan kegiatan terdiri atas empat tahap yaitu: (1) tahap persiapan, (2) tahap pelatihan, (3) tahap pendampingan dan (4) tahap evaluasi. Tahap persiapan meliputi tahap observasi lokasi, wawancara, perijinan serta persiapan materi pelatihan, alat dan bahan. Pada tahap observasi, dilakukan analisis situasi yang berupa survei ke lokasi mitra untuk mengetahui kondisi di sana. Kegiatan survei dilakukan pada bulan JuliAgustus 2019, di mana pada saat itu bertepatan dengan pendampingan mahasiswa KKN Universitas Hasyim Asy'ari Tebuireng Jombang. Kegiatan selanjutnya yang dilakukan adalah wawancara dengan kepala desa setempat. Setelah didapatkan data hasil observasi dan wawancara, ditemukan beberapa permasalahan yang terjadi di lokasi mitra. Selanjutnya, dicarikan solusi terbaik untuk mengatasi permasalahan yang timbul dengan berkonsultasi bersama kepala desa. Solusi yang ditawarkan kepada mitra berupa pelatihan dan pendampingan budidaya tanaman dengan sistem hidroponik.

Tahap selanjutnya adalah pelatihan tentang sistem hidroponik yang dilaksanakan 
pada tanggal 12-13 Desember 2019 pukul 11.00 WIB. Tahap pelatihan berupa pemberian materi tentang sistem hidroponik oleh tim PKM. Tahap ketiga adalah pendampingan terhadap praktik budidaya tanaman dengan hidroponik yang dilakukan oleh ibu-ibu anggota PKK. Kegiatan pendampingan dilakukan sekitar satu bulan karena menunggu sampai sayuran hidroponik tumbuh. Tahap terakhir yaitu evaluasi. Evaluasi dilakukan terhadap kegiatan PKM mulai dari persiapan, selama proses pelaksanaan sampai dengan akhir kegiatan.

Adapun indikator keberhasilan kegiatan PKM ini ditentukan sebagai berikut.

1. Partisipasi peserta.

Indikator keberhasilan kegiatan PKM dikatakan tercapai apabila diikuti oleh minimal 80\% sasaran PKM.

2. Tingkat pemahaman peserta.

Indikator keberhasilan kegiatan PKM dikatakan tercapai apabila minimal $80 \%$ sasaran PKM memahami sistem budidaya hidroponik. Untuk mengukur tingkat pemahaman peserta dilihat dari keaktifan peserta dalam kegiatan pelatihan, diskusi dan tanya jawab saat pelatihan. Selain itu juga digunakan angket yang berisi pernyataan berkaitan dengan materi dan pelaksanaan pelatihan.

3. Tingkat keterampilan peserta.

Kegiatan PKM ini dikatakan berhasil mencapai indikator apabila $80 \%$ peserta PKM dapat mempraktikkan budidaya tanaman hidroponik.

\section{HASIL DAN PEMBAHASAN}

Berdasarkan kegiatan pengabdian kepada masyarakat yang telah dilakukan dipaparkan hasil sebagai berikut. https://doi.org/10.21067/jpm.v6i1.5382

\section{Kegiatan Pelatihan dan Pendampingan PKM}

Pada hari pertama kegiatan pelatihan berupa pemberian materi tentang teknik budidaya tanaman secara hidroponik. Pemateri memaparkan berbagai keunggulan sistem hidroponik dibandingkan bertanam secara konvensional.

Sebagaimana yang dijelaskan oleh Iqbal (2016) bahwa nilai lebih budidaya dengan sistem hidroponik adalah sebagai berikut: 1) jenis tanaman yang dapat dibudidayakan dan media yang dapat digunakan sangat beragam, 2) fleksibel dan dapat dilakukan dimana saja, 3) skala usaha dapat disesuaikan dengan lahan yang tersedia dan kemampuan mengelola, 4) pertumbuhan tanaman sangat cepat, 5) produksi tanaman lebih banyak dan berkualitas, 6) dapat ditanam dengan pola penanaman vertikal (vertikultur), 7) sayuran yang dihasilkan lebih segar, bersih higienis sehingga memiliki nilai ekonomis tinggi, 8) perawatan tanaman relatif mudah, 9) membutuhkan tenaga kerja yang lebih sedikit, 10) tanaman relatif terhindar dari hama, jamur dan penyakit, 11) ramah lingkungan, 12) perawatan tanaman lebih terkontrol, 13) penggunaan pupuk lebih hemat, efektif dan efisien, serta 14) dapat diposisikan sebagai hobi maupun pekerjaan utama.

Pada hari kedua dilaksanakan praktik penanaman sayuran secara hidroponik. Kegiatan ini mendapat respon yang baik dari peserta PKM, di mana peserta antusias mengikuti jalannya kegiatan. Pada kegiatan praktik menanam sayuran hidroponik, sistem budidaya hidroponik yang diterapkan adalah jenis NFT (Nutrient Film Technique) menggunakan metode substrat dengan teknik irigasi manual. Substrat yang digunakan berupa rockwool. Berdasarkan pemaparan Kaleka (2019), prinsip hidroponik sistem NFT yaitu melalui pelarutan unsur hara lalu dialirkan pada instalasi hidroponik berupa 
pipa paralon yang sudah dilubangi dengan aliran yang dangkal pada ketebalan arus sekitar 4-5 mm.

Adapun alasan penggunaan hidroponik sistem NFT adalah mudah diterapkan, seperti yang disampaikan Kaleka (2019) bahwa para pemula atau pekebun lebih banyak menggunakan sistem NFT sebab mudah dalam pengoperasian. Sistem ini lebih bersifat fleksibel sebab mudah untuk dimodifikasi dengan bermacam variasi sesuai lokasi di mana instalasi tersebut diletakkan. Tidak hanya itu, Kaleka (2019) juga memaparkan bahwa hidroponik sistem NFT menyediakan tingkat keberhasilan lebih baik untuk para pemula, utamanya pada skala rumah tangga. Dengan adanya keberhasilan bagi para pemula, ini akan menumbuhkan semangat agar terus mencoba bermacam cara yang terbaik untuk mendapatkan bahan makanan yang berkualitas.

Pada awal praktik, tim PKM menyediakan alat dan bahan hidroponik sebagai sampel untuk memudahkan pemahaman masyarakat tentang teknik hidroponik. Pada hari yang sama sekaligus dilakukan penyemaian benih sayuran yang berupa kangkung, sawi dan bayam pada substrat rockwool. Jenis sayuran yang dapat ditanam secara hidroponik seperti sawi, selada, kangkung, bayam dkk., 2018; Siregar, 2017; Tallei dkk., 2017). Selain sayuran, tanaman lain yang dapat dibudidayakan dengan hidroponik yaitu buah, tanaman obat, tanaman hias dan jenis tanaman yang termasuk tanaman tahunan maupun semusim (Tallei dkk., 2017). Lebih lanjut, tanaman herbal yang cocok ditanam secara hidroponik seperti jahe, sirih, daun dewa dkk., 2018).

Selanjutnya, menunggu hasil penyemaian benih selama kurang lebih 7 hari hingga benih tumbuh menghasilkan 1-2 daun. Benih yang sudah tumbuh dimasukkan dalam gelas plastik sisa minuman instan, setelah itu ditumbuhkan dalam pipa paralon yang sudah dilubangi.

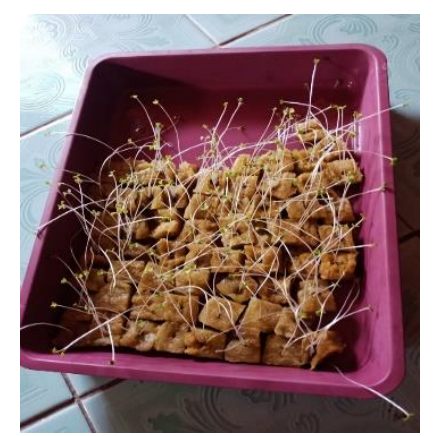

Gambar 1. Penyemaian Benih Umur 4 Hari

Kegiatan penyemaian benih kemudian dilanjutkan dengan pendampingan praktik yang dilakukan peserta PKM sesuai materi yang sudah diberikan. Ketika praktik, peralatan disediakan oleh peserta, untuk benih sayuran dari tim PKM. Pendampingan dilaksanakan meliputi perakitan instalasi, pemeliharaan tanaman sampai pemanenan.

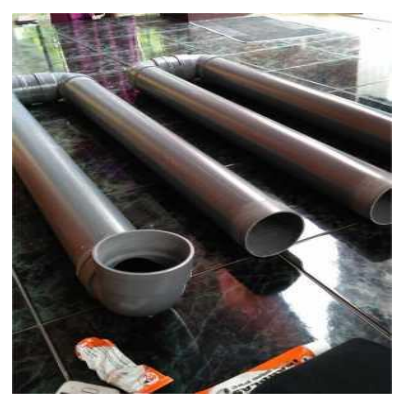

Gambar 2. Alat-alat Pembuatan Hidroponik

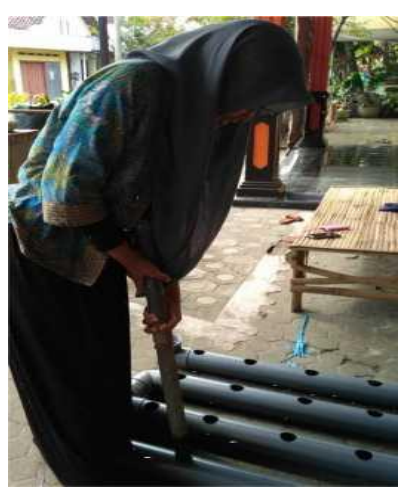

Gambar 3. Kegiatan Melubangi Pipa Paralon 


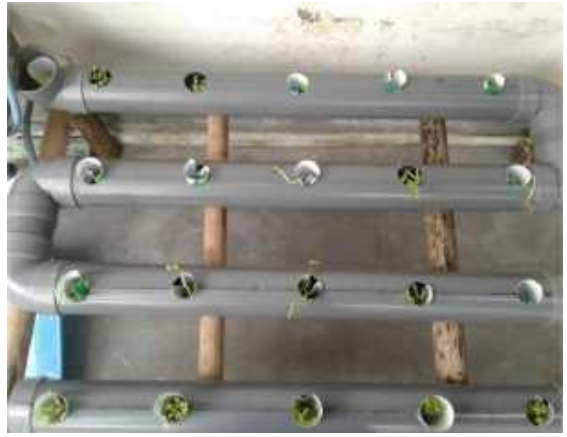

Gambar 4. Perkembangan Benih dalam Netpot

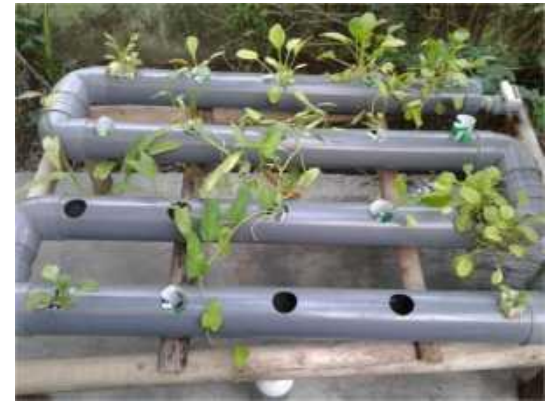

Gambar 5. Sayuran Hidroponik Berumur 50 Hari

Evaluasi merupakan tahap akhir kegiatan PKM ini. Evaluasi dari tahap persiapan berupa kesulitan dalam mengkondisikan peserta PKM yang berakibat penambahan durasi pelaksanaan pelatihan. Sebagai bahan evaluasi, hal ini dapat digunakan untuk perbaikan agar pelaksanaannya tepat waktu.

Evaluasi dari tahap pelatihan yaitu kurang kondusifnya kegiatan karena banyak anak kecil, sehingga mengganggu konsentrasi para peserta PKM. Walaupun demikian, peserta sangat antusias dan aktif selama kegiatan berlangsung.

Evaluasi dari tahapan praktik oleh peserta yaitu perlu diusahakan agar dilakukan pengecekan setiap hari ke lokasi untuk memastikan sejauh mana perkembangan dari tanaman hidroponik. Dari kegiatan ini, diperoleh hasil adanya sebagian tanaman hidroponik dalam netpot yang mengalami keterlambatan dalam pertumbuhannya dan tertinggal dari tanaman lain. Kemungkinan ini diakibatkan kurang teraturnya irigasi dan pemberian nutrisi karena tergantung waktu luang yang dimiliki peserta PKM. Selain itu, perlu juga evaluasi tentang bagaimana cara mendorong peserta PKM supaya berkenan menyusun instalasi untuk hidroponik serta yang terpenting adalah tidak mengalami kendala dalam hal biaya.

\section{Ketercapaian Indikator}

Setelah dilakukan pelatihan
mengenai budidaya tanaman secara
hidroponik, selanjutnya untuk mengetahui
ketercapaian indikator adalah dengan
membandingkan pengetahuan dan keterampilan peserta setelah mengikuti kegiatan pelatihan dan praktik budidaya tanaman dengan hidroponik berdasarkan indikator yang telah ditentukan yang meliputi partisipasi peserta, tingkat pemahaman peserta dan tingkat keterampilan peserta dalam menerapkan sistem hidroponik. Keberhasilan indikator dijabarkan sebagai berikut.

\section{a. Partisipasi peserta}

Dengan memperhatikan daftar hadir peserta pelatihan, dapat diketahui bahwa sebanyak 25 orang hadir mengikuti kegiatan ini atau dapat dikatakan mencapai $100 \%$. Dengan demikian dapat disimpulkan bahwa indikator partisipasi peserta PKM mencapai keberhasilan.

b. Tingkat pemahaman peserta

Berdasarkan hasil diskusi dan tanya jawab setelah pemberian materi pelatihan dan analisis hasil angket yang diberikan setelah kegiatan pelatihan menunjukkan bahwa $92 \%$ peserta PKM telah memahami materi budidaya sayuran sistem hidroponik. Peserta pelatihan tampak antusias dan aktif berpartisipasi selama kegiatan diskusi dan tanya jawab. Selain itu juga didukung dengan kemampuan peserta dalam mempraktikkan sistem hidroponik. Maka 
ditarik kesimpulan bahwa indikator tingkat pemahaman peserta telah berhasil dicapai.

\section{c. Tingkat keterampilan peserta}

Berdasarkan kemampuan peserta dalam perakitan alat, penanaman benih dan pemeliharaan sampai pemanenan, didapatkan data $84 \%$ peserta telah mampu mempraktikkan sistem budidaya sayuran hidroponik. Dengan demikian disimpulkan bahwa indikator yang ketiga yaitu tingkat keterampilan peserta dalam menerapkan sistem hidroponik telah berhasil dicapai.

Dengan keberhasilan indikator kegiatan PKM ini diharapkan peserta PKM selanjutnya secara individu dapat menerapkan sistem budidaya hidroponik di rumahnya masing-masing agar dapat memenuhi kebutuhan sayuran skala rumah tangga. Sejalan dengan kegiatan pelatihan metode hidroponik yang dilakukan oleh Sunardi dkk. (2019), memberikan hasil bahwa warga dapat bertanam secara hidroponik serta mampu memenuhi kebutuhan sayur rumah tangganya. Kegiatan pelatihan yang dilakukan (Halim \& Yunita, 2019) menunjukkan hasil bahwa metode hidroponik dapat diterapkan dan dimanfaatkan oleh warga sehingga mampu meningkatkan perekonomian warga. Adapun hasil pelatihan hidroponik yang dilakukan Nugraha (2019) mampu meningkatkan pengetahuan dan ketrampilan mitra sasaran dalam memanfaatkan lahan kosong untuk sumber pangan dan alternatif penghasilan melalui teknik hidroponik. Bahkan, dari kegiatan PKM yang dilakukan Saputra dkk. (2018) telah menghasilkan kelompokkelompok bercocok tanam dengan hidroponik di setiap RT sehingga terbentuk desa wisata hidroponik.

\section{Kendala yang Dihadapi}

Kendala yang dialami dalam kegiatan PKM ini terkait perakitan alat dan bahan untuk instalasi hidroponik bagi peserta PKM. Berkaitan dengan hal tersebut, Kaleka (2019) menyampaikan bahwa kekurangan dari hidroponik sistem NFT salah satunya adalah biaya yang diperlukan untuk pembuatan instalasi seperti pembelian pipa paralon atau talang untuk bedengan penanaman.

\section{PENUTUP}

\section{Simpulan}

Berdasarkan kegiatan Pengabdian Kepada Masyarakat (PKM) yang dilakukan, dapat disimpulkan sebagai berikut.

1. Tingkat partisipasi peserta tercapai $100 \%$.

2. Ketercapaian tingkat pemahaman peserta sebesar $92 \%$.

3. Sebesar $84 \%$ peserta terampil melakukan budidaya sayuran hidroponik.

\section{Saran}

Dari kegiatan ini diberikan saran yaitu perlu dilaksanakan kegiatan pendampingan secara berkelanjutan hingga masyarakat benarbenar bisa memenuhi kebutuhan sayur secara mandiri. Selain itu tanaman yang dibudidayakan juga dapat lebih bervariasi.

\section{Ucapan Terima Kasih}

Ucapan terima kasih ditujukan kepada Universitas Hasyim Asy'ari Tebuireng Jombang atas pendanaan yang diberikan berdasarkan Kontrak Penelitian dan Pengabdian Kepada Masyarakat Nomor: 229/LPPM-UNHASY/X/2019 tahun anggaran 2019. 


\section{E. DAFTAR PUSTAKA}

Hakimah, E. ., Sardanto, R., \& Subagyo. (2017). Pemberdayaan Masyarakat melalui Pelatihan Hidroponik Membentuk Wirausahawan Baru pada Perum Kuwak Utara Kelurahan Ngadirejo Kota Kediri. Jurnal Abdinus, 1(1), 75-82.

Halim, L., \& Yunita, I. (2019). Strategi Pelatihan Hidroponik sebagai Pemberdayaan Masyarakat yang Bernilai Ekonomis. Patria, 1(2), 69-76.

Handayani, F., Sapri, \& Ansyori, A. K. (2018). Pelatihan Budidaya Sayur Organik dan Tanaman Herbal Organik Berbasis Teknik Hidroponik. Jurnal Abdimas Mahakam, 2(2), 57-64.

Hutagalung, I. (2017). Pelestarian Lingkungan melalui Tanaman Hidroponik (Budidaya Tanaman Hidroponik di Kelurahan Rawa Buaya dan Kembangan Utara, Jakarta Barat). Konferensi Nasional Ke-3 Pengabdian Kepada Masyarakat Dan Corporate Sosial Responsibility, Oktober, 269 280.

Iqbal, M. (2016). Simpel Hidroponik. Yogyakarta: Lily Publisher.

Kaleka, N. (2019). Hidroponik Sumbu Wick \& Rakit Apung. Yogyakarta: Pustaka Baru Press.

Malau, A. G., Yuliastrin, A., Simanjuntak, H., \& Gulo, E. (2018). Meningkatkan Keterampilan Bercocok Tanam dengan Metode Hidroponik di Kelurahan Mukakuning, Kota Batam. Seminar Nasional Pengabdian Kepada Masyarakat Universitas Terbuka, 1, 18-24. https://doi.org/10.21067/jpm.v6i1.5382

Natalia, C., Kusumarini, Y., \& Poillot, J. F. (2017). Perancangan Interior Fasilitas Edukasi Hidroponik Di Surabaya. Intra, 5(2), 97-106.

Nugraha, A. W. (2019). Pemberdayaan Masyarakat Desa Sumberdadi dengan Pelatihan Hidroponik dan Pupuk Organik. JPP IPTEK (Jurnal Pengabdian Dan Penerapan IPTEK), 3(1), 25-32.

Nurdin. (2018). Pelatihan Sistem Pertanian Hidroponik pada Skala Rumah Tangga di Kelurahan Dutulanaa Kabupaten Gorontalo. Laporan Pengabdian kepada Masyarakat. Gorontalo: Universitas Negeri Gorontalo.

Roidah, I. S. (2014). Pemanfaatan Lahan dengan Menggunakan Sistem Hidroponik. Jurnal Universitas Tulungagung BONOROWO, 1(2), 4350 .

Saputra, H., Rudianto, Setiawan, D., \& Nugroho, R. A. (2018). Desa Wisata Hidroponik sebagai Upaya Pemberdayaan Masyarakat Desa Sidomulyo Kecamatan Anggana Kabupaten Kutai Kartanegara. Jurnal Pengabdian Kepada Masyarakat, 24(1), 587-593.

Sariwati, A., Shofi, M., \& Badriah, L. (2019). Pelatihan Pemanfaatan Limbah Botol Plastik sebagai Media Pertumbuhan Tanaman Hidroponik. Journal of Community Engagement and Empowerment, 1(1), 6-13.

Siregar, M. (2017). Respon Pemberian Nutrisi Abmix pada Sistem Tanam Hidroponik terhadap Pertumbuhan dan Produksi Tanaman Sawi (Brassica 


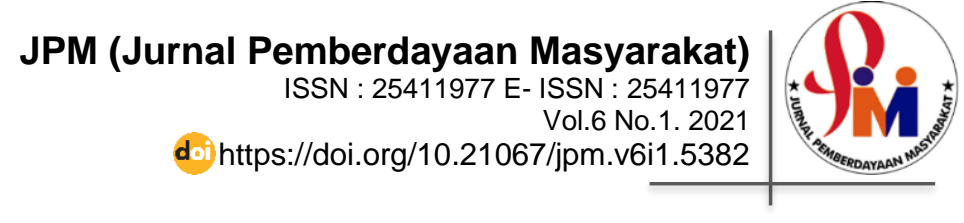

juncea). Journal of Animal Science and Agronomy Panca Budi, 2(2), 18-24.

Solikhah, B., Suryarini, T., \& Wahyudin, A. (2018). Pemberdayaan Ibu Rumah Tangga melalui Pelatihan Hidroponik. Jurnal Abdimas, 22(2), 121-128.

Sunardi, Istikowati, W. T., \& Pujawati, E. D. (2019). Pelatihan Budidaya Sayur dengan Metode Hidroponik di Desa Guntung Payung, Banjarbaru. PengabdianMu: Jurnal Ilmiah Pengabdian Kepada Masyarakat, 4(1), 40-45.

Susilawati. (2019). Dasar-Dasar Bertanam secara Hidroponik. Palembang: UNSRI Press.

Swastika, S., Yulfida, A., \& Sumitro, Y. (2018). Budidaya Sayuran Hidroponik: Bertanam Tanpa Media Tanah. Balai Pengkajian Teknologi Pertanian (BPTP) Balitbangtan Riau, Badan Penelitian dan Pengembangan Pertanian, Kementerian Pertanian.http://riau.litbang.pertanian.g o.id/kopitani/images/pdf/juknis/juknish idroponik.pdf

Tallei, T., Rumengan, I. F. M., \& Adam, A. A. (2017). Hidroponik untuk Pemula. Manado: UNSRAT Press. 